\title{
Effect of Family Caregiving on Depression in the First 3 Months After Spinal Cord Injury
}

\author{
Min-Gu Kang, MD, Chul-Hyun Kim, MD, Eunhee Park, MD, Jae-Won Huh, MD, \\ Won-Jong Yang, MD, Tae-Woo Nam, MD, Yu-Sun Min, MD, Tae-Du Jung, MD \\ Department of Rehabilitation Medicine, Kyungpook National University Hospital, Daegu, Korea
}

Objective To investigate the effect of family caregiving on depression in the first 3 months after spinal cord injury (SCI).

Methods A retrospective study was carried out on 76 patients diagnosed with an SCI from January 2013 to December 2016 at the Department of Physical Medicine and Rehabilitation of Kyungpook National University Hospital, Korea. Clinical characteristics including age, gender, level of injury, completeness of the injury, time since injury, caregiver information, etiology, and functional data were collected through a retrospective review of medical records. Depression was assessed using the Beck Depression Inventory (BDI). Patients with 14 or more points were classified as depressed and those with scores of 13 or less as non-depressed group.

Results Of the 76 patients, 33 were in the depressed group with an average BDI of $21.27 \pm 6.17$ and 43 patients included in the non-depressed group with an average BDI of $4.56 \pm 4.20$. The BDI score of patients cared by unlicensed assistive personnel (UAP) was significantly higher than that of patients cared by their families $(p=0.020)$. Univariate regression analysis showed that motor complete injury ( $p=0.027)$, UAP caregiving $(p=0.022)$, and Ambulatory Motor Index ( $\mathrm{p}=0.019)$ were associated with depression after SCI. Multivariate binary logistic regression analysis showed that motor completeness $(\mathrm{p}=0.002)$ and UAP caregiving $(\mathrm{p}=0.002)$ were independent risk factors.

Conclusion Compared with UAP, family caregivers lowered the prevalence of depression in the first 3 months after SCI.

Keywords Depression, Spinal cord injuries, Caregivers

Received April 22, 2017; Accepted June 2, 2017

Corresponding author: Tae-Du Jung

Department of Rehabilitation Medicine, Kyungpook National University Hospital, 130 Dongdeok-ro, Jung-gu, Daegu 41944, Korea. Tel: +82-53-2005311, Fax: +82-53-423-0389, E-mail: teeed0522@hanmail.net

ORCID: Min-Gu Kang (http://orcid.org/0000-0002-0680-9607); Chul-Hyun Kim (http://orcid.org/0000-0003-0309-1473); Eunhee Park (http://orcid. org/0000-0001-6553-2321); Jae-Won Huh (http://orcid.org/0000-0002-3351-6340); Won-Jong Yang (http://orcid.org/0000-0002-2711-3318); Tae-Woo Nam (http://orcid.org/0000-0002-7581-5015); Yu-Sun Min (http://orcid.org/0000-0003-0373-0538); Tae-Du Jung (http://orcid.org/0000-0002-16368665).

() This is an open-access article distributed under the terms of the Creative Commons Attribution Non-Commercial License (http://creativecommons.org/ licenses/by-nc/4.0) which permits unrestricted noncommercial use, distribution, and reproduction in any medium, provided the original work is properly cited. Copyright $\odot 2018$ by Korean Academy of Rehabilitation Medicine 


\section{INTRODUCTION}

Depression is the most common psychological complication of spinal cord injury (SCI) [1], and is known to adversely affect the physical rehabilitation process [2]. SCI is associated with weakness, sensory dysfunction, impaired respiratory function, neurogenic bladder or bowel, sexual dysfunction, and chronic pain, which lead to reduced mobility and function, and impairment of social and vocational roles [3,4]. Depression has been known to exacerbate these complications [5].

Depression is considered highly prevalent among SCI patients, and the estimated prevalence varies from $10 \%$ $27 \%$ [6-9] partly due to the diversity of depression measures and different cut-off values. A recent meta-analysis of current studies revealed that the estimated mean prevalence of depression after SCI was $22.2 \%$ (range, $18.7 \%$ 26.3\%) [10]. However, most participants in those studies were patients with chronic SCI. In this study, we focused on SCI patients in the first 3 months and investigated the prevalence of depression in acute and sub-acute cases.

The role of caregivers in SCI rehabilitation is critical to rehabilitation. Caregivers not only take care of the patient's physical well-being, but also provide emotional support [11]. Traditionally, family members played a key role in caring for patients; however, the rapidly changing social structure has transferred that role to non-family care workers [12]. Ahn et al. [13] found that family caregiving lowered the risk of depression after a stroke. However, this relationship has yet to be studied in the context of SCI.

Therefore, we sought to investigate the caregiving approaches among SCI patients and compared the risk of depression between patients cared for by family and those cared for by non-family care workers.

\section{MATERIALS AND METHODS}

\section{Participants}

Patients with SCI admitted to the Department of Rehabilitation Medicine of Kyungpook National University Hospital from January 1, 2013 to December 31, 2016 were retrospectively identified. We selected 76 patients who had received at least 2 weeks of inpatient SCI rehabilitation and were injured within a maximum of 3 months.

Inclusion criteria were: (1) age of 16 years or older, (2) a first episode of SCI within 3 months, (3) at least 2 weeks of inpatient SCI rehabilitation, and (4) no previous psychological history. Exclusion criteria were: (1) cognitive impairment (Mini-Mental State Examination $<20$ ), and (2) presence of other central nervous system disease.

This study was approved by the Institutional Review Board of Kyungpook National University Hospital (No. 2017-03-004).

\section{Clinical measurements}

Clinical characteristics of participants including age, gender, level of injury and completeness of the injury, time since injury, caregiver information, etiology and functional data were collected through retrospective chart review (RCR). We defined caregivers as those who had mainly assisted the patient with activities of daily living (ADL) for at least the past 2 weeks. We classified the patients into two groups. The patients cared for by family members were classified as the family caregiving group and those cared for by non-family care workers as the unlicensed assistive personnel (UAP) caregiving group. UAP refers to personnel who assist the patient under the supervision of licensed nurses.

Neurological examination was conducted by rehabilitation physicians using the International Standards for Neurological Classification of Spinal Cord Injury developed by the American Spinal Injury Association (ASIA). A rating of A or B on the ASIA impairment scale (AIS) indicates motor complete injury whereas $\mathrm{C}$ or $\mathrm{D}$ is considered as motor incomplete injury.

Depression was assessed using the Beck Depression Inventory (BDI). The BDI consists of 21 self-reported questionnaires. Items are rated on 4-point scales, and the total score ranges from 0 to 63 . A cut-off score of 14 is used to validate the differences between depressed and non-depressed patients [14]. Thus, we divided patients into two groups using the cut-off score of 14 in this study. Patients with 14 or more points were classified as the depressed group and those with scores of 13 or less as the non-depressed group.

The balance function was assessed using the Berg Balance Scale (BBS). The BBS consists of 14 items that assess the ability to maintain positions or complete movement tasks of varying difficulty. The score of each item ranges from 0 to 4, and the sum score ranges from 0 to 56 [15]. The BBS has proved to be reliable in patients with SCI [16]. 
Functional status was evaluated by the Modified Barthel Index (MBI) and Ambulatory Motor Index (AMI). The MBI is used to assess the ability to perform ADL. Ten items are evaluated including functions of bowel, bladder, grooming, toilet use, feeding, transfer, walking, dressing, climbing stairs, and bathing. The MBI has been used extensively in SCI research [17] and is considered to show validity [18]. The AMI, derived from strength grades of hip and knee muscles, has been used as a clinical pre-

Table 1. Clinical characteristics of the participants $(n=76)$

\begin{tabular}{|cc}
\hline \multicolumn{1}{|c}{ Characteristic } & Value \\
\hline Age (yr) & $54.28 \pm 14.53$ \\
\hline Sex & $55(72.4)$ \\
\hline Male & $21(27.6)$ \\
\hline Female & \\
\hline ASIA impairment scale & $10(13.2)$ \\
\hline A & $8(10.5)$ \\
\hline B & $15(19.7)$ \\
\hline C & $43(56.6)$ \\
\hline D & \\
\hline Lesion location & $50(65.8)$ \\
\hline Cervical & $19(25.0)$ \\
\hline Thoracic & $7(9.2)$ \\
\hline Lumbar & \\
\hline Caregiver type & $48(63.2)$ \\
\hline Family & $28(36.8)$ \\
\hline Unlicensed assistant personnel & \\
\hline Etiology & $62(81.6)$ \\
\hline Traumatic & $14(18.4)$ \\
\hline Non-traumatic & $33(43.4)$ \\
\hline Depression & $43(56.6)$ \\
\hline Depressed (BDI $\geq 14)$ & $11.82 \pm 9.78$ \\
\hline Non-depressed (BDI $<14)$ & $27.30 \pm 2.37$ \\
\hline BDI & $25.63 \pm 22.75$ \\
\hline MMSE & $47.91 \pm 32.74$ \\
\hline BBS & $50.96 \pm 34.18$ \\
\hline MBI & $45.41 \pm 18.04$ \\
\hline AMI & \\
\hline Time since injury (day) & \\
\hline
\end{tabular}

Values are presented as mean \pm standard deviation or number (\%).

ASIA, American Spinal Injury Association; BDI, Beck Depression Inventory; MMSE, Mini-Mental State Examination; MBI, Modified Barthel Index; BBS, Berg Balance Scale; AMI, Ambulatory Motor Index. dictor of functional mobility [19].

\section{Statistical analyses}

Two-tailed t-tests were used to compare parametric data, and Mann-Whitney tests were used for nonparametric data. Categorical variables were compared using chi-square or Fisher exact tests. To identify the risk factors predicting depression after SCI, a binary logistic regression analysis was conducted. The associations between various factors and depression were determined using univariate binary logistic regression analysis. The variables with a p-value less than 0.5 were included in a multivariable binary logistic regression model to identify independent risk factors. Statistical analyses were performed using the SPSS version 20.0 (IBM SPSS Inc., Armonk, NY, USA). A p-value less than 0.5 was considered statistically significant.

\section{RESULTS}

The 76 study subjects included 55 male and 21 female patients. The mean age was $54.28 \pm 14.53$ years, and the mean time since the injury was $45.41 \pm 18.04$ days. The most common injury level was cervical, followed by thoracic and lumbar injuries. Forty-eight patients were cared for by family members and 28 patients were cared for by UAP. Depressive symptoms were identified in 33 patients and the average BDI score was $11.82 \pm 9.78$. The clinical characteristics of the participants are listed in Table 1.

Family caregivers included spouses, adult children, parents, siblings, and adult grandchildren (Fig. 1).

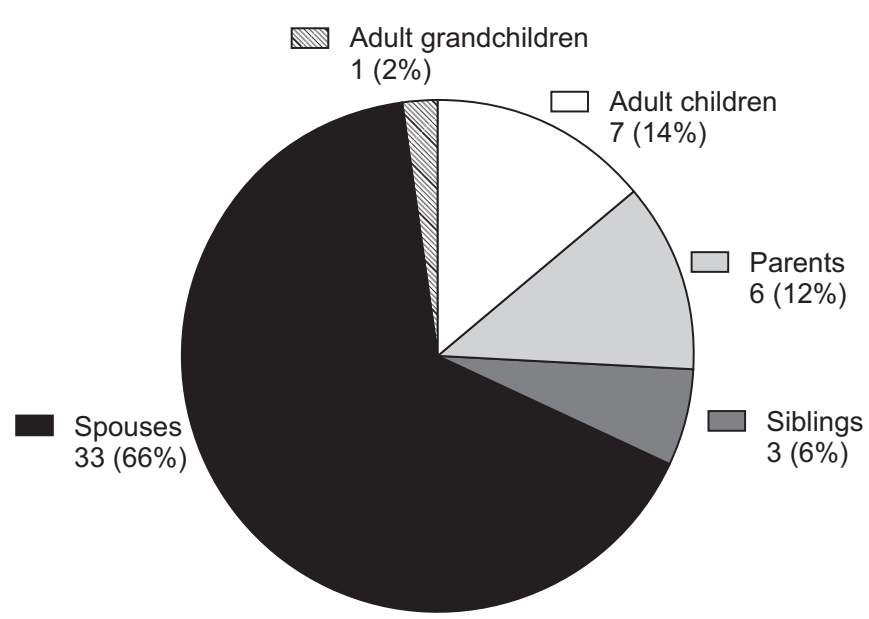

Fig. 1. Pie chart showing the distribution of family caregivers. 
The association between various factors and caregiver types is shown in Table 2 . The BDI score was significantly higher in the UAP caregiving group than in the family caregiving group ( $\mathrm{p}=0.02)$. Other factors were not significantly associated between each group.

Univariate binary logistic regression showed that motor completeness (odds ratio $[\mathrm{OR}]=3.524 ; 95 \%$ confidence interval $[\mathrm{CI}], 1.153-10.765 ; \mathrm{p}=0.027$ ), UAP caregiving ( $\mathrm{OR}=$ 3.091; 95\% CI, 1.175-8.130; $\mathrm{p}=0.022)$, and AMI ( $\mathrm{OR}=0.983$; 95\% CI, 0.969-0.997, $\mathrm{p}=0.019$ ) were significantly associated with depression after SCI. Multivariate analysis of the significant risk factors revealed that motor completeness (OR=7.821; 95\% CI, 2.108-29.011, $\mathrm{p}=0.002)$ and UAP caregiving ( $\mathrm{OR}=6.282 ; 95 \% \mathrm{CI}, 1.973-19.995 ; \mathrm{p}=0.002)$ were independent risk factors for depression post-SCI. However, AMI was not an independent risk factor for predicting depression in multivariate analysis. Logistic regression analysis is detailed in Table 3.

\section{DISCUSSION}

The prevalence of depression in SCI patients during

Table 2. Comparison between patients in the UAP and family caregiving groups

\begin{tabular}{lccc}
\hline & UAP caregiving $(\mathbf{n}=\mathbf{2 8})$ & Family caregiving $(\mathbf{n}=\mathbf{4 8})$ & p-value \\
\hline Age $(\mathrm{yr})$ & $55.36 \pm 15.34$ & $53.65 \pm 14.17$ & 0.624 \\
MMSE & $26.79 \pm 2.81$ & $27.60 \pm 2.05$ & 0.148 \\
BDI & $15.21 \pm 8.20$ & $9.83 \pm 10.16$ & $0.020^{*}$ \\
BBS & $21.07 \pm 20.42$ & $28.29 \pm 23.81$ & 0.167 \\
MBI & $48.14 \pm 29.62$ & $47.77 \pm 34.72$ & 0.962 \\
AMI & $50.95 \pm 26.56$ & $50.97 \pm 38.20$ & 0.998 \\
Time since injury (day) & $46.57 \pm 17.98$ & $44.73 \pm 18.22$ & 0.670 \\
\hline
\end{tabular}

Values are presented as mean \pm standard deviation.

UAP, unlicensed assistive personnel; MMSE, Mini-Mental State Examination; BDI, Beck Depression Inventory; BBS, Berg Balance Scale; MBI, Modified Barthel Index; AMI, Ambulatory Motor Index.

${ }^{*} \mathrm{p}<0.05$.

Table 3. Binary logistic regression of the variable factors for predicting depression after spinal cord injury

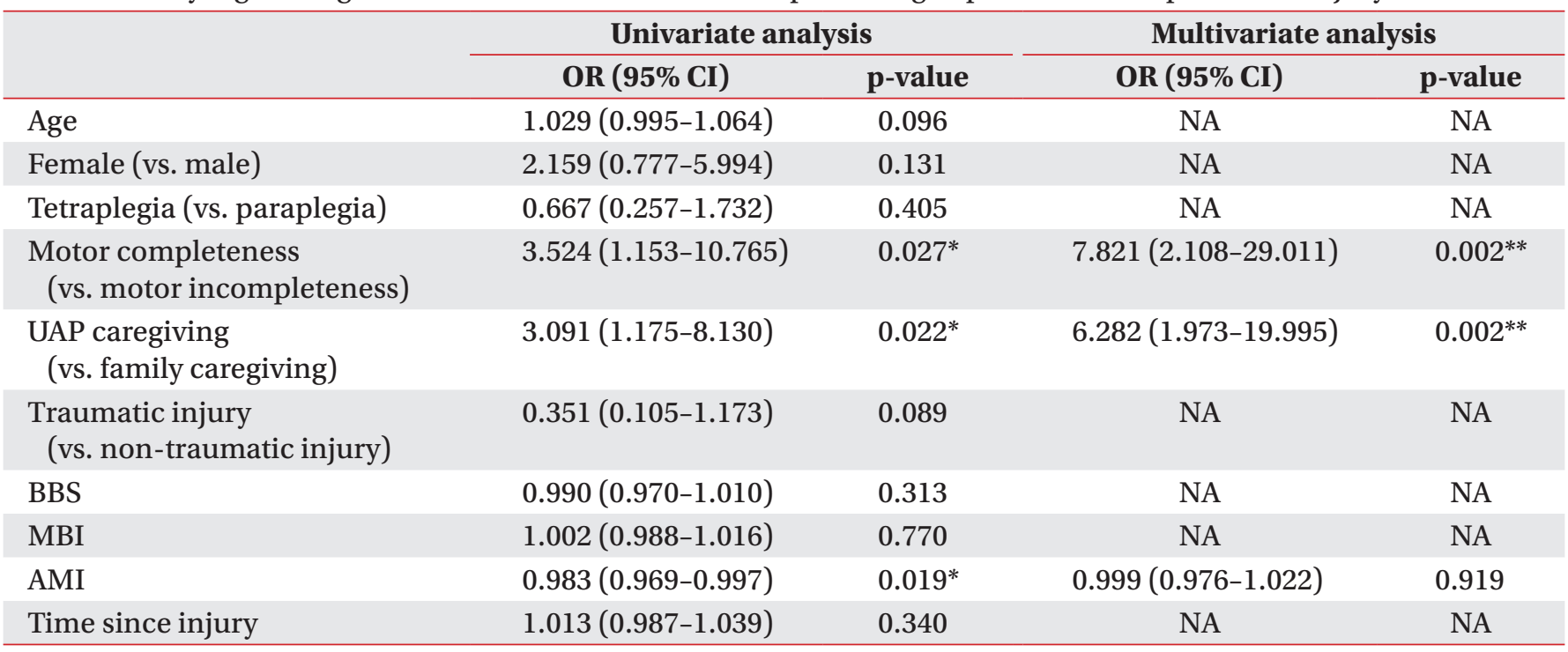

OR, odds ratio; CI, confidence interval; AIS, American Spinal Injury Association (ASIA) Impairment Scale; UAP, unlicensed assistive personnel; BBS, Berg Balance Scale; MBI, Modified Barthel Index; AMI, Ambulatory Motor Index; NA, not applicable.

${ }^{*} \mathrm{p}<0.05,{ }^{* *} \mathrm{p}<0.01$. 
the first three months was $43 \%$ in this study, which is greater than in the general medical population $[20,21]$. It is consistent with previous studies in that SCI patients are prone to depression [6-10]. SCI is a devastating injury for the patients as well as their family members, and depression after SCI may aggravate the morbidity. Therefore, the high prevalence of depression after SCI underscores the need for screening and treatment of all the patients during SCI rehabilitation, especially in acute or subacute phases.

Our study also found that motor complete injury increased the risk of depression. Previous studies suggested that injury severity was not related to the risk of depression after SCI [22], which is inconsistent with our findings. As the patients in this study were diagnosed with an SCI within 3 months, those with motor incomplete injury were likely to be on the path to recovery. The expectation of recovery contributed to alleviation of depression after SCI as shown in a previous study [23].

In this study, family caregiving was associated with lower rates of depression after SCI. To our knowledge, this is the first study to compare the prevalence of depression among SCI patients cared by family and UAP. Most of the previous studies focused on the caregivers' depression. Instead, we focused on the relation between each caregiver type and patients' depression. Consequently, this study suggests that patients with family caregivers are at a lower risk of depression after SCI.

A few previous studies emphasized the role of family members in caring for patients $[24,25]$. Family caregiving offers functional assistance, social support, and emotional encouragement. Patients feel secure with their family, so their assistance might prove better in restoration of locomotion and balance [24]. In addition, family members know their patients best, which may contribute to effective motivation and encouragement. Tsouna et al. also reported that high emotional support provided by family caregivers significantly affected rehabilitation process [26]. Dissatisfaction with care workers might affect depression and rehabilitation adversely. Lee et al. [27] reported that a low degree of satisfaction with care workers might result in early discharge from rehabilitation hospital.

Though family caregiving has specific advantages, it is not without weaknesses. Most family caregivers assume their role without preparation and faced distressing situations, such as financial strain, physical stress, and emotional distress $[28,29]$. Occasionally, they may abandon their jobs, particularly when patients stayed longer at hospitals or became disabled, which implied that the adversity deprived the family of two members' income. Legal nursing leave for families of SCI patients might be helpful to prevent these situations. Moreover, their anxiety could be exacerbated by a lack of knowledge of measures to assist the patients physically and emotionally after discharge. Therefore, caregivers may need financial support, legal nursing leave, and periodic consultations with pain physicians and psychologists, and appropriate education to provide care. We hope that policymakers and healthcare providers consider the needs of family caregivers.

The Korean Ministry of Health and Welfare established a comprehensive nursing care service to reduce the role of family caregivers by providing comprehensive care services through professional nursing staff [30]. However, this system is associated with expansion of nursing personnel, appropriate compensation for nurses, and the risk of potential safety hazards, such as falls. Expansion of the role of caregivers is expected to further increase the physical and emotional stress of nurses [31]. In addition, nurses may not be able to stay with the patients to talk and provide emotional support. In other words, comprehensive care services cannot completely replace family caregivers.

There are some limitations in this study despite its novelty and focus on the type of caregivers, and the consequences thereof. First, the small sample size requires cautious interpretation. Second, only the BDI was used as a measure of depressive symptoms. The BDI measures depression severity, but does not necessarily correspond to major depressive disorder according to the Diagnostic and Statistical Manual of Mental Disorders (DSM) criteria. Nevertheless, in clinical situations, the BDI has been widely used as a screening measure and researchers have attempted to determine cut-off scores to indicate clinical depression [32]. Moreover, the consistency of internal coefficients of BDI was excellent in previous studies $[33,34]$. Third, we failed to consider the socioeconomic indicators, such as education, income, and marital status. Further studies are required to confirm the findings in this study. Fourth, this study focused only on acute and sub-acute patients. Longitudinal studies suggested that depression scores after SCI increased gradually until 
48 weeks $[5,35]$. Therefore, the caregiver burden might be greater in the chronic phase, and longitudinal studies need to investigate the impact of caregiver type on chronic SCI patients.

In summary, depression is highly prevalent in SCI patients during the first 3 months and motor complete injuries increased the risk of depression. Furthermore, family caregiving is associated with a lower risk of depression after SCI. Therefore, compared with UAP caregiving, family caregiving lowers the risk of depression after SCI, at least in the first 3 months. We expect that these findings will be considered during family consultation, especially in the acute or sub-acute phases.

\section{CONFLICT OF INTEREST}

No potential conflict of interest relevant to this article was reported.

\section{REFERENCES}

1. Elliott TR, Frank RG. Depression following spinal cord injury. Arch Phys Med Rehabil 1996;77:816-23.

2. Aoki T, Hosaka T, Ishida A. Psychiatric evaluation of physical rehabilitation patients. Gen Hosp Psychiatry 1995;17:440-3.

3. Boekamp JR, Overholser JC, Schubert DS. Depression following a spinal cord injury. Int J Psychiatry Med 1996;26:329-49.

4. Craig A, Tran Y, Middleton J. Psychological morbidity and spinal cord injury: a systematic review. Spinal Cord 2009;47:108-14.

5. Malec J, Neimeyer R. Psychologic prediction of duration of inpatient spinal cord injury rehabilitation and performance of self-care. Arch Phys Med Rehabil 1983; 64:359-63.

6. Bombardier CH, Fann JR, Tate DG, Richards JS, Wilson CS, Warren AM, et al. An exploration of modifiable risk factors for depression after spinal cord injury: which factors should we target? Arch Phys Med Rehabil 2012;93:775-81.

7. Banerjea R, Findley PA, Smith B, Findley T, Sambamoorthi U. Co-occurring medical and mental illness and substance use disorders among veteran clinic users with spinal cord injury patients with complexities. Spinal Cord 2009;47:789-95.
8. Findley PA, Banerjea R, Sambamoorthi U. Excess mortality associated with mental illness and substance use disorders among veteran clinic users with spinal cord injury. Disabil Rehabil 2011;33:1608-15.

9. Judd FK, Brown DJ. Psychiatric consultation in a spinal injuries unit. Aust N Z J Psychiatry 1992;26:218-22.

10. Williams R, Murray A. Prevalence of depression after spinal cord injury: a meta-analysis. Arch Phys Med Rehabil 2015;96:133-40.

11. Pellatt GC. Perceptions of the nursing role in spinal cord injury rehabilitation. Br J Nurs 2003;12:292-9.

12. Lee HS. Caregiver burden in caring for elders before and after long-term care service in Korea. J Korean Acad Nurs 2012;42:236-47.

13. Ahn DH, Lee YJ, Jeong JH, Kim YR, Park JB. The effect of post-stroke depression on rehabilitation outcome and the impact of caregiver type as a factor of poststroke depression. Ann Rehabil Med 2015;39:74-80.

14. Beck AT, Ward CH, Mendelson M, Mock J, Erbaugh J. An inventory for measuring depression. Arch Gen Psychiatry 1961;4:561-71.

15. Berg KO, Wood-Dauphinee SL, Williams JI, Maki B. Measuring balance in the elderly: validation of an instrument. Can J Public Health 1992;83 Suppl 2:S7-11.

16. Wirz M, Müller R, Bastiaenen C. Falls in persons with spinal cord injury: validity and reliability of the Berg Balance Scale. Neurorehabil Neural Repair 2010;24:70-7.

17. Yarkony GM, Roth EJ, Heinemann AW, Wu YC, Katz RT, Lovell L. Benefits of rehabilitation for traumatic spinal cord injury. Multivariate analysis in 711 patients. Arch Neurol 1987;44:93-6.

18. Roth E, Davidoff G, Haughton J, Ardner M. Functional assessment in spinal cord injury: a comparison of the Modified Barthel Index and the 'adapted' Functional Independence Measure. Clin Rehabil 1990;4:277-85.

19. Waters RL, Yakura JS, Adkins RH. Gait performance after spinal cord injury. Clin Orthop Relat Res 1993;288: 87-96.

20. Kessler RC, Berglund P, Demler O, Jin R, Koretz D, Merikangas KR, et al. The epidemiology of major depressive disorder: results from the National Comorbidity Survey Replication (NCS-R). JAMA 2003;289: 3095-105.

21. Kessler RC, Berglund P, Demler O, Jin R, Merikangas $\mathrm{KR}$, Walters EE. Lifetime prevalence and age-of-onset 
distributions of DSM-IV disorders in the National Comorbidity Survey Replication. Arch Gen Psychiatry 2005;62:593-602.

22. Craig AR, Hancock KM, Dickson HG. Spinal cord injury: a search for determinants of depression two years after the event. Br J Clin Psychol 1994;33(Pt 2):221-30.

23. Shin JC, Goo HR, Yu SJ, Kim DH, Yoon SY. Depression and quality of life in patients within the first 6 months after the spinal cord injury. Ann Rehabil Med 2012; 36:119-25.

24. Boltz M, Capezuti E, Shabbat N. Nursing staff perceptions of physical function in hospitalized older adults. Appl Nurs Res 2011;24:215-22.

25. Shapiro J. Family reactions and coping strategies in response to the physically ill or handicapped child: a review. Soc Sci Med 1983;17:913-31.

26. Tsouna-Hadjis E, Vemmos KN, Zakopoulos N, Stamatelopoulos S. First-stroke recovery process: the role of family social support. Arch Phys Med Rehabil 2000;81: 881-7.

27. Lee JH, Kwon WA, Lee JH, Min DK. An investigation of selection and transfer factors on the admission of rehabilitation hospital. J Korea Acad Ind Coop Soc 2013; 14:2819-27.

28. Dickson A, O'Brien G, Ward R, Allan D, O'Carroll R. The impact of assuming the primary caregiver role following traumatic spinal cord injury: an interpreta- tive phenomenological analysis of the spouse's experience. Psychol Health 2010;25:1101-20.

29. Weitzenkamp DA, Gerhart KA, Charlifue SW, Whiteneck GG, Savic G. Spouses of spinal cord injury survivors: the added impact of caregiving. Arch Phys Med Rehabil 1997;78:822-7.

30. Lee HJ, Chai CG. A study on the use and circulation of comprehensive care ward in S public hospital. J Korea Inst Healthc Archit 2015;21:27-36.

31. Lee E, Chang SS. Factors influencing depression of nurses among comprehensive nursing care service ward. Korean J Occup Health Nurs 2016;25:340-51.

32. Kalpakjian CZ, Bombardier CH, Schomer K, Brown PA, Johnson KL. Measuring depression in persons with spinal cord injury: a systematic review. J Spinal Cord Med 2009;32:6-24.

33. Radnitz CL, McGrath RE, Tirch DD, Willard J, PerezStrumolo L, Festa J, et al. Use of the beck depression inventory in veterans with spinal cord injury. Rehabil Psychol 1997;42:93-101.

34. Ferington FE. Personal control and coping effectiveness in spinal cord injured persons. Res Nurs Health 1986;9:257-65.

35. Kennedy P, Rogers BA. Anxiety and depression after spinal cord injury: a longitudinal analysis. Arch Phys Med Rehabil 2000;81:932-7. 